\title{
Interactive effects of depth and marine protection on predation and herbivory patterns
}

\author{
Adriana Vergés ${ }^{1,2, *, * *}$, Fiona Tomas ${ }^{3, * *}$, Enric Ballesteros ${ }^{4}$ \\ ${ }^{1}$ Centre for Marine Bio-Innovation, Evolution and Ecology Research Centre, School of Biological, Earth and \\ Environmental Sciences, University of New South Wales, Sydney, New South Wales 2052, Australia \\ ${ }^{2}$ Sydney Institute of Marine Science, Mosman, New South Wales 2088, Australia \\ ${ }^{3}$ Institut Mediterrani d'Estudis Avançats (CSIC), Carrer Miquel Marqués 21, 07190 Esporles, Illes Balears, Spain \\ ${ }^{4}$ Centre d'Estudis Avançats de Blanes (CSIC), Accés a la Cala Sant Francesc 14, 17300 Blanes, Girona, Spain
}

\begin{abstract}
The establishment of marine protected areas (MPAs) worldwide has shown that closure of areas to fishing results in major changes in the structure of marine ecosystems. The removal of high-order consumers by fishing has both direct and indirect effects that can lead to important changes in the strength of trophic interactions. Although the effects of marine protection on biological interactions are beginning to be understood, our knowledge is largely restricted to shallow-water assemblages. However, depth gradients are also characterised by significant differences in the intensity of trophic linkages, and these may be interacting with any effects derived from protection. In this study, the individual and combined effects of depth and marine reserve protection on predation and herbivory were determined across 3 regions in the NW Mediterranean (Catalunya, Mallorca and Menorca) using juvenile urchins and palatable algae as bioassays. Marine protection did not strongly influence fish herbivory, which generally decreased with depth. We found no evidence of depth-related changes in predation rates or the size of predatory fishes, but there was a strong effect of protection on predation rates that was only consistently observed across regions in shallow water $(5 \mathrm{~m}$ depth), but not at greater depths (15 and $30 \mathrm{~m}$ ). This increase in predation of sea urchins within MPAs in shallow waters can have important community-wide consequences, as herbivorous sea urchins are commonly most abundant in these shallow habitats and predator-urchin interactions have important cascading effects on algal communities.
\end{abstract}

KEY WORDS: Marine reserves $\cdot$ Sea urchins $\cdot$ Macroalgae $\cdot$ Mediterranean Sea $\cdot$ Fish herbivory Cystoseira spp.

Resale or republication not permitted without written consent of the publisher

\section{INTRODUCTION}

Biological interactions are among the most important forces structuring ecological communities, and depend not only on specific characteristics of the interacting species, but also on environmental conditions. Indeed, it has long been recognised that community structure and the distribution of species strongly depend on the interplay of biotic processes and abiotic environmental conditions, whereby the intensity and relative importance of species interactions is often mediated by the environment (Connell
1975, Menge \& Sutherland 1987, Menge \& Olson 1990). For example, the physical stress of water turbulence is known to determine the relative importance of predation and competition in rocky intertidal regions (Menge \& Sutherland 1987, Menge \& Farrell 1989).

In marine communities, the establishment of marine protected areas (MPAs) where fishing and other extractive activities are not permitted commonly increases the density, biomass and average size of the species targeted by fishing (Bell 1983, Garcia-Rubies \& Zabala 1990, Francour 1994, Harmelin et al. 1995, 
Edgar \& Barrett 1997, Willis et al. 2003). Since most targeted species are predators, recovery of these populations often leads to increased predation within the borders of the reserve (McClanahan et al. 1999, Shears \& Babcock 2002, Guidetti 2006, Clemente et al. 2010). In turn, increased predation can decrease the abundance of herbivorous prey such as sea urchins, and thus indirectly increase algal abundance via trophic cascades (Pinnegar et al. 2000, Shears \& Babcock 2003, Guidetti \& Sala 2007). Although both the direct and indirect effects of marine protection on biological interactions are starting to be understood thanks to long-term time series of ecological data (Babcock et al. 2010), our knowledge is largely restricted to shallow waters $(\leq 15 \mathrm{~m})$. However, depth gradients are also characterised by significant differences in the intensity of trophic linkages (Hay et al. 1983, Witman 1987, Witman \& Dayton 2001), and we know little about how these may be interacting with any effects derived from protection.

In subtidal marine communities, herbivory and predation pressure are usually lowest at shallow wave-exposed sites because turbulence associated with wave impact and water movement limits the feeding ability of most mobile consumers (Witman \& Dayton 2001). Herbivory is often greatest a few meters below the surface and decreases thereafter with depth, as algal resources become scarcer due to light limitation (Hay et al. 1983, Brokovich et al. 2010). Predation by invertebrates is often also highest in the first meters of water, as subtidal predators track the abundance of prey such as mussels (Sloan \& Aldridge 1981, Witman \& Grange 1998). In contrast, predation by fishes is often considered to increase in deeper waters. For example, tethering experiments have repeatedly shown an increase in predation with depth in estuaries (McIvor \& Odum 1988, Ruiz et al. 1993, but see Baker \& Sheaves 2007). These studies provide support for the shallow-water refuge hypothesis (SWRH), which predicts that shallow-water nursery habitats in estuarine waters provide vulnerable juvenile fish and other prey with a refuge from predation. SWRH studies are mostly restricted to depths $<5 \mathrm{~m}$ and propose that shallow water acts as a refuge for smaller fish by excluding larger fish that prey on them or by reducing the efficiency of predators (Ruiz et al. 1993). However, tests of the SWRH at greater depths in non-estuarine conditions have also found an increase in predation from $1-5 \mathrm{~m}$ to ca. $20 \mathrm{~m}$ depth (Linehan et al. 2001, Ryer et al. 2010). This increase in predation with depth has been associated with a general increase in the mean size of predatory fishes in deeper waters, a phenomenon generally applicable to demersal fishes (Macpherson \& Duarte 1991).

In this study, we quantified the individual and combined effects of protection from fishing and depth on herbivory and predation across 3 regions in the NW Mediterranean using bioassays. We predicted a decrease in fish herbivory with depth irrespective of protection, as herbivorous fish are not a target of fishing activities in the NW Mediterranean. Because recreational and artisanal fishing effort generally decreases with depth in the NW Mediterranean (Morales-Nin et al. 2005, Stelzenmuller et al. 2007) and shallow areas have been recently shown to be more sensitive to protection (Claudet et al. 2011), we predicted an interactive effect of protection and depth on relative predation rates, with higher predation in shallower water inside MPAs and equal levels of predation in deeper waters irrespective of protection. Further, we performed underwater visual censuses and recorded the size and total biomass of herbivorous and predatory fish assemblages at all sites and depths, inside and outside MPAs, and tested whether fish size increases with depth (down to $30 \mathrm{~m}$ ) within coastal benthic communities in the NW Mediterranean.

\section{MATERIALS AND METHODS}

\section{Study sites}

This study was conducted in 3 regions of the NW Mediterranean Sea: Mallorca, Menorca and Catalunya (Fig. 1). One MPA and one nearby unprotected area (UA) of similar environmental characteristics were selected within each region (Fig. 1). The 3 MPAs differ in how long they have been protected Medes Islands in Catalunya has been protected since 1983, Cabrera National Park in Mallorca since 1991 and north of Menorca since 1999 - but fish recovery has been observed in all MPAs (Garcia-Rubies \& Zabala 1990, García-Charton et al. 2004, Cardona et al. 2007), although none are likely to have reached full recovery (Guidetti \& Sala 2007). Within each region, 3 sites were sampled at 3 depths $(5,15$ and $30 \mathrm{~m}$ ) on algal-dominated rocky habitats in the summer, when fish abundance and activity tend to be highest (Sala \& Zabala 1996, Tomas et al. 2005, Prado et al. 2007). Site selection was based on a good working knowledge of the area and taking into consideration wave exposure (all sites were in relatively waveexposed points) and slope (gentle regular slope; i.e. we avoided sites with 'vertical walls'). 


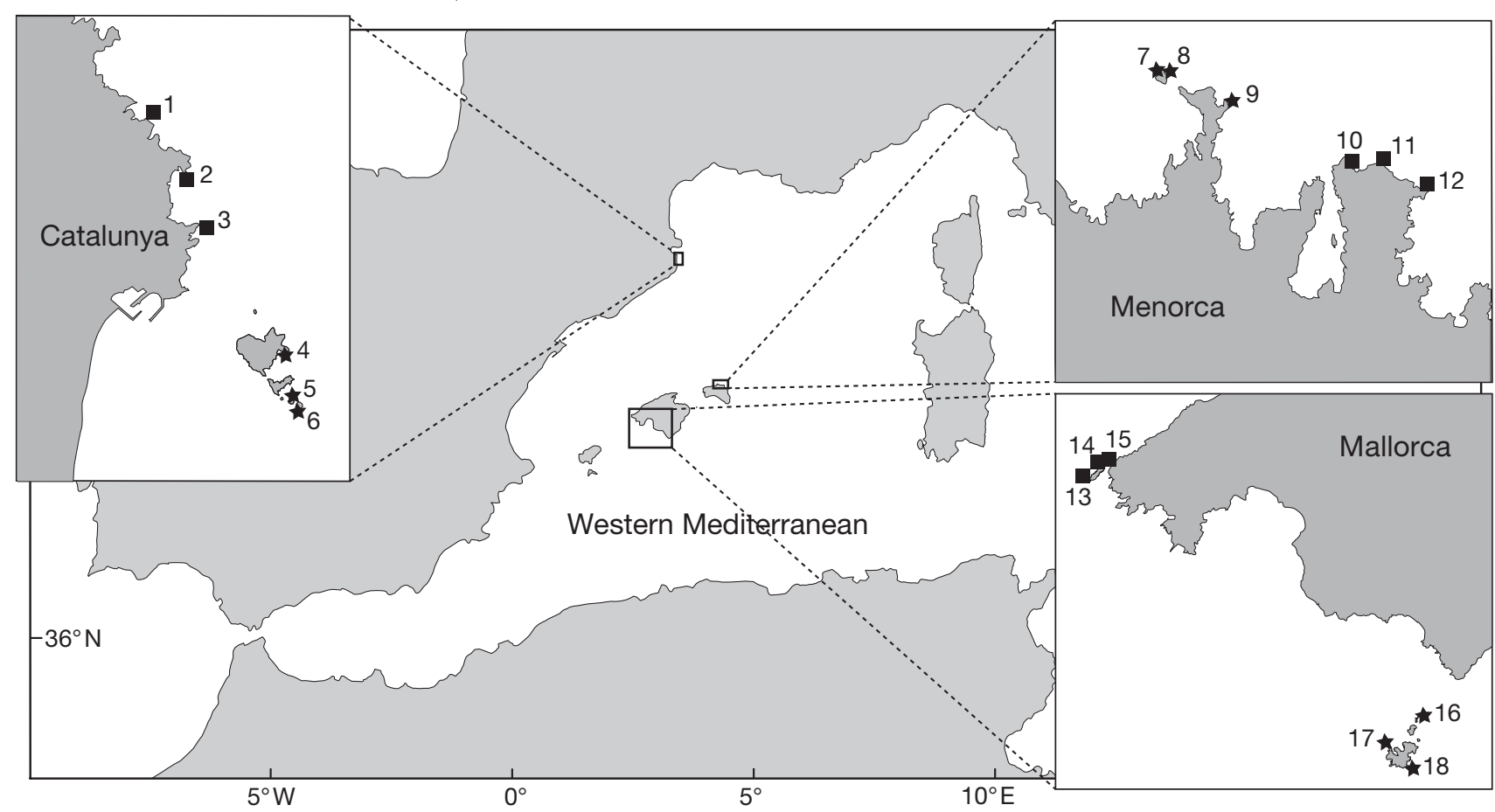

Fig. 1. Location of the marine protected areas (stars) and unprotected sites (squares) in the 3 regions studied (Mallorca, Menorca and Catalunya). Site positions are indicated by numbers (1 to 18)

\section{Consumption bioassays}

Relative differences in herbivory and predation between different depths and between protected and unprotected areas were measured using bioassay experiments. Relative rates of herbivory were quantified using 2 ecologically equivalent and vicariant species of the genus Cystoseira: C. mediterranea in Catalunya and $C$. amentacea var. stricta (hereafter $C$. stricta) in Menorca and Mallorca. Both species are highly preferred by the sparid fish Sarpa salpa (Vergés et al. 2009, A.Vergés pers. obs.), the only strictly herbivorous fish in the NW Mediterranean (Verlaque 1990, Sala \& Boudouresque 1997, Pinnegar \& Polunin 2000, Ruitton et al. 2000). Five groups of 5 individual thalli of similar size and biomass $(\sim 3 \mathrm{~g}$ wet mass) were tethered to the benthos at each site and depth using cable ties, and the percentage of thalli consumed per group in $24 \mathrm{~h}$ was measured. To ensure that all herbivory was due to fish consumption, we manually removed any sea urchins found close to experimental specimens (within at least a $5 \mathrm{~m}$ radius). Thalli were only considered consumed when obvious signs of herbivory were observed, i.e. over half of the thallus was eaten. Predation bioassays were conducted using juvenile individuals (between 4 and $10 \mathrm{~mm}$ in test diameter) of the common sea urchin Paracentrotus lividus. To ensure pre- dation trials were comparable across depths and sites, we placed juvenile urchins on a $20 \times 20 \mathrm{~cm}^{2}$ patch that was cleared of all erect algae and devoid of any refuges, and any mobile invertebrates found in the vicinity (within a $2 \mathrm{~m}$ radius) that could potentially predate on the urchins were manually removed. Four sea urchins were placed in the centre of the cleared benthos in each trial and the percentage of individuals eaten after 10 min was counted. Four predation trials per depth and site combination were conducted.

The distribution of the Cystoseira spp. used in our bioassays is restricted to the upper sublittoral $(0 \mathrm{~m})$ in wave-exposed shores, where they are out of reach from the herbivorous fish Sarpa salpa (Vergés et al. 2009, A. Vergés pers. obs.). Similarly, juvenile sea urchins are usually cryptic, sheltered within crevices or beneath boulders and out of reach of carnivorous fishes (Hereu et al. 2004, Farina et al. 2009). In our bioassays, we made the algae and the urchins more vulnerable by placing them within the reach of their predators. Consequently, both alga and juvenile urchin bioassays measured relative potential herbivory/predation pressure rates rather than absolute rates because of the artefact of altered vulnerability of both prey items, as happens with tethering assays (Aronson \& Heck 1995). This effect of increased vulnerability is 
assumed to be constant across all treatments (region, protection and depth), and we therefore consider that the relative potential herbivory/predation pressure measured in this study reflects patterns in actual herbivory/predation pressure.

\section{Fish censuses}

Underwater visual censuses were performed to quantify fish community composition and fish biomass. Fishes were counted and their size (total length) was estimated along three $50 \times 5 \mathrm{~m}^{2}$ transects for each site and depth (Harmelin-Vivien et al. 1985). All fish counts were performed by the same experienced diver (E. Ballesteros) and small-sized cryptic species (belonging to families Gobiidae, Callyonimidae, Bleniidae, Gobioesocidae and Tripterygidae) were not included in the censuses to avoid biases (García-Charton \& Pérez-Ruzafa 2001). We identified 31 species from the families Labridae, Moronidae, Mugilidae, Sciaenidae, Serranidae and Sparidae. Fish abundance was transformed to biomass (g $250 \mathrm{~m}^{-2}$ ) using length-mass allometries (Morato et al. 2001, Froese \& Pauly 2005). When there was no information for the species of interest, allometric values from a congeneric sympatric species with similar morphology and size range were used (this happened with Labrus viridis, where we used allometric values from L. merula, and for Symphodus doderleini, where we used allometric values from Symphodus rostratus). Total herbivorous fish biomass was considered as the biomass of Sarpa salpa, the only strictly herbivorous fish in the Western Mediterranean, where it has a key role in structuring seagrass and algal communities (Tomas et al. 2005, Vergés et al. 2009, Tomas et al. 2011). Total urchin predator biomass was calculated by combining the biomass values of the main consumers of the urchin Paracentrotus lividus in the NW Mediterranean, which include the following 10 species: Coris julis, Diplodus sargus, D. vulgaris, L. merula, L. viridis, Sparus aurata, Symphodus mediterraneaus, Symphodus roissali, Symphodus tinca and Thalassoma pavo (Boudouresque \& Verlaque 2001). Analyses of size structure of fishes were performed on the 3 most important predators of the urchin P. lividus combined: D. sargus, D. vulgaris and C. julis (together responsible for $99 \%$ of predation in our study regions; Sala 1997). Abundance of fishes was recorded for small, medium and large individuals of each species. Each size class was defined as one-third of the maximum and minimum total length range.

\section{Statistical analyses}

Spatial variations in herbivore and predator pressure (bioassays) and abundances (in terms of biomass; $g$ fresh mass [FM] $\times 250 \mathrm{~m}^{-2}$ ) were assessed using 4way nested ANOVAs with region as a random factor, protection and depth as fixed orthogonal factors, and site as a random factor nested in the interaction between region and protection (see Table 2). Data in all analyses were balanced and, prior to statistical analyses, normality and homogeneity of variance were checked, and data were transformed when necessary to meet assumptions (all transformations performed prior to analysis are reported in the statistical tables of results). When overall significant differences were detected, a posteriori pair-wise comparisons of means were performed using the Student-Newman-Keuls (SNK) test. ANOVAs were performed using the statistical package GMAV (coded by A. J. Underwood \& M. G. Chapman, University of Sydney, Australia).

Multivariate differences in fish assemblages (in terms of biomass per species) were calculated using a 4-way nested permutational multivariate ANOVA (PERMANOVA) with the same design described above and Bray-Curtis as our distance metric. Permutational tests of multivariate dispersion (PERMDISP; Anderson et al. 2008) were used to check the homogeneity in the average dissimilarities of samples of all groups (region, protection, site and depth; 54 groups). Although homogeneity of multivariate dispersion is an assumption of PERMANOVA, this test is considered to be robust to some heterogeneity in dispersion (Anderson et al. 2008).

Finally, PERMANOVA was also used to analyse multivariate differences in the size-frequency distributions of each of the 3 main sea urchin predators (Diplodus sargus, D. vulgaris and Coris julis) across regions, protections, depths and sites. We used the same design described above, with the number of individuals of the 3 size classes as our variables and Euclidean distance as the metric. All multivariate statistical analyses were performed using Primer-E v6 software (Clarke \& Gorley 2006) with the PERMANOVA+ add-on package (version 1.0.1; Anderson et al. 2008).

\section{RESULTS}

\section{Patterns in relative herbivory and predation}

Herbivory tended to be higher in shallow $(5 \mathrm{~m})$ waters in all regions (Fig. 2A), but this effect was not consistent across all sites (significant interaction term 

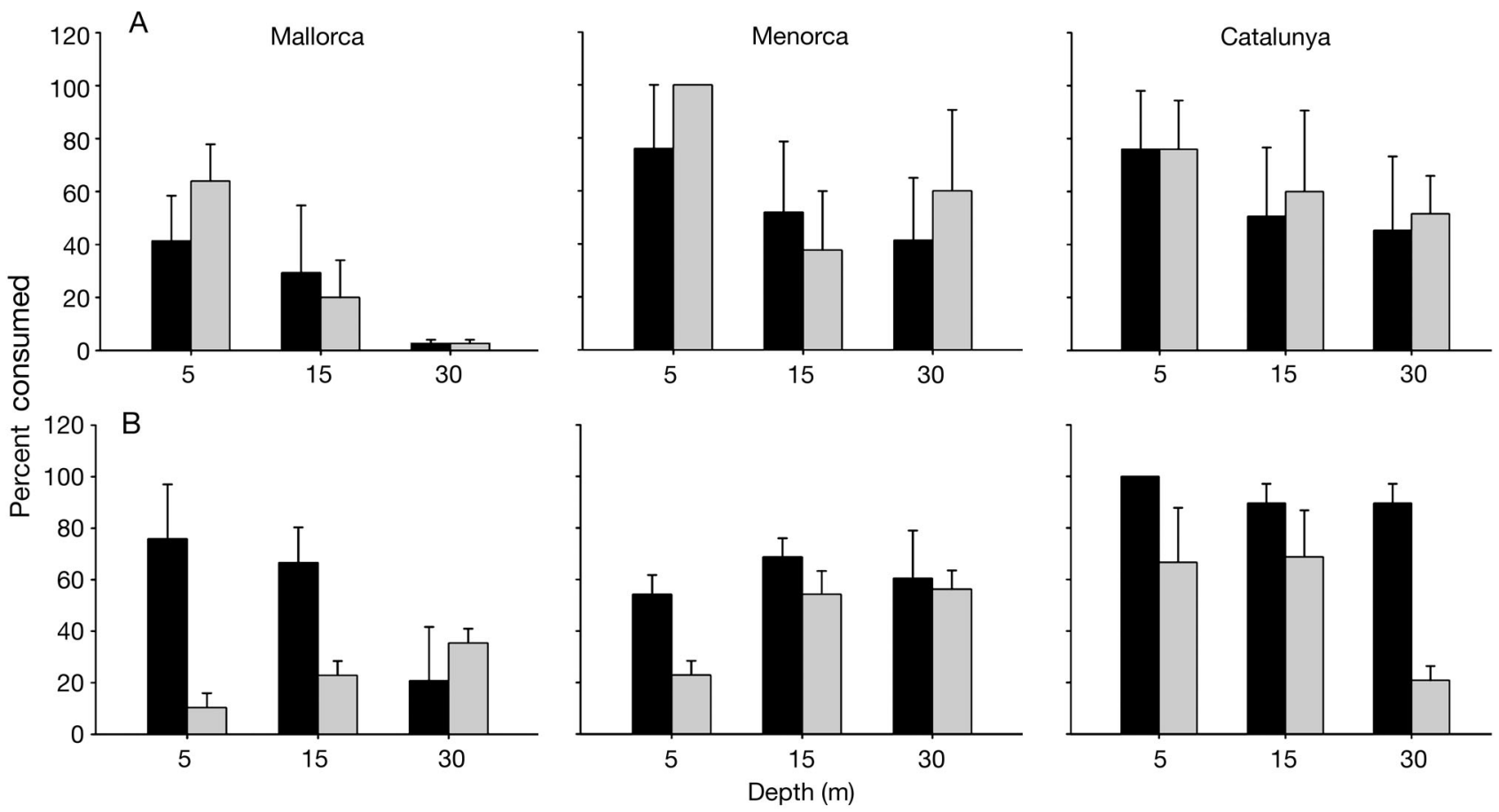

Fig. 2. Depth $(5,15$ and $30 \mathrm{~m})$ patterns of $(\mathrm{A})$ herbivory and (B) predation pressure (mean $+\mathrm{SE}$ ) in marine protected areas (black bars) and unprotected areas (grey bars) areas in the 3 regions studied (ordered from south to north; Mallorca, Menorca and Catalunya)

depth $\times$ site, Table 1). We detected a near-significant effect of protection on patterns of herbivory $(\mathrm{p}=$ 0.055 ; Table 1), with UAs tending to have slightly higher rates of herbivory than MPAs (Fig. 2A). Predation rates were strongly influenced by an interaction between region, protection and depth (Table 1). To explore this interaction, we compared levels of protection (MPA and UA) and depth (5, 15 and $30 \mathrm{~m}$ ) within each region (Mallorca, Menorca and Catalunya) using SNK tests. We found that in shallow waters $(5 \mathrm{~m})$, predation rates were greater in MPAs than in UAs in all the 3 regions (SNK, $\mathrm{p}<0.05$ for all 3 comparisons; Fig. 2B), whereas at greater depths $(15$ and $30 \mathrm{~m})$ protection did not have a consistent effect across regions (Fig. 2B).

\section{Fish distribution patterns}

Total herbivorous fish biomass was influenced by an interaction between region, protection and depth (Table 2, Fig. 3A). SNK tests of the effect of protec-

Table 1. Nested ANOVA comparing rates of herbivory and urchin predation among regions (R), depth (D), protection (P), site (S) and their interactions. All data were log-transformed prior to analyses. Bold text indicates a significant effect at $\mathrm{p}<0.05$

\begin{tabular}{|c|c|c|c|c|c|c|c|c|c|}
\hline \multirow{2}{*}{$\begin{array}{l}\text { Source } \\
\text { of variation }\end{array}$} & \multicolumn{4}{|c|}{ Herbivory - } & \multicolumn{4}{|c|}{ Urchin predation -} & \multirow{2}{*}{$\begin{array}{l}\text { Denominator } \\
F \text {-test }\end{array}$} \\
\hline & $\mathrm{df}$ & MS & F & $\mathrm{p}$ & $\mathrm{df}$ & MS & $F$ & $\mathrm{p}$ & \\
\hline Region & 2 & 34487 & 4.29 & 0.039 & 2 & 20867 & 5.92 & 0.016 & $\mathrm{~S}(\mathrm{R} \times \mathrm{P})$ \\
\hline Protection & 1 & 2739 & 16.82 & 0.055 & 1 & 47704 & 17.65 & 0.052 & $\mathrm{R} \times \mathrm{P}$ \\
\hline Site $(\mathrm{R} \times \mathrm{P})$ & 12 & 8039 & 13.12 & $<0.001$ & 12 & 3523 & 3.83 & $<0.001$ & Residual \\
\hline Depth & 2 & 36915 & 16.29 & 0.012 & 2 & 3834 & 1.03 & 0.435 & $\mathrm{R} \times \mathrm{D}$ \\
\hline $\mathrm{R} \times \mathrm{P}$ & 2 & 163 & 0.02 & 0.980 & 2 & 2702 & 0.77 & 0.486 & $\mathrm{~S}(\mathrm{R} \times \mathrm{P})$ \\
\hline $\mathrm{R} \times \mathrm{D}$ & 4 & 2266 & 0.38 & 0.822 & 4 & 3712 & 4 & 0.013 & $\mathrm{D} \times \mathrm{S}(\mathrm{R} \times \mathrm{P})$ \\
\hline $\mathrm{P} \times \mathrm{D}$ & 2 & 2391 & 1.57 & 0.314 & 2 & 2718 & 0.44 & 0.672 & $\mathrm{R} \times \mathrm{P} \times \mathrm{D}$ \\
\hline $\mathrm{D} \times \mathrm{S}(\mathrm{R} \times \mathrm{P})$ & 24 & 5995 & 9.78 & $<0.001$ & 24 & 928 & 1.01 & 0.459 & Residual \\
\hline $\mathrm{R} \times \mathrm{P} \times \mathrm{D}$ & 4 & 1522 & 0.25 & 0.904 & 4 & 6190 & 6.67 & $<0.001$ & $\mathrm{D} \times \mathrm{S}(\mathrm{R} \times \mathrm{P})$ \\
\hline Residual & 216 & 613 & & & 162 & 921 & & & \\
\hline
\end{tabular}


Table 2. Nested univariate ANOVAs comparing total biomass of herbivorous fish (Sarpa salpa), total biomass of urchin predatory fish, and results of nested multivariate PERMANOVA comparing the fish community composition among regions (R), depth (D), protection (P), site (S) and their interactions. Prior to analyses, total biomass data were log-transformed and multivariate fish community composition data were square-root transformed. Denominator terms for $F$-tests in the analysis are given in Table 1. Bold text indicates a significant effect at $\mathrm{p}<0.05$

\begin{tabular}{|c|c|c|c|c|c|c|c|c|c|c|}
\hline \multirow{2}{*}{$\begin{array}{l}\text { Source of } \\
\text { variation }\end{array}$} & \multirow[t]{2}{*}{ df } & \multicolumn{3}{|c|}{ — Herbivore biomass -} & \multicolumn{3}{|c|}{ — Urchin predator biomass - } & \multicolumn{3}{|c|}{ — Fish assemblages } \\
\hline & & MS & $F$ & $\mathrm{p}$ & MS & $F$ & $\mathrm{p}$ & MS & Pseudo- $F$ & $\mathrm{p}$ \\
\hline Region & 2 & 18.31 & 1.16 & 0.347 & 10.16 & 8.76 & 0.005 & 24173 & 16.64 & 0.001 \\
\hline Protection & 1 & 36.77 & 0.64 & 0.509 & 5.24 & 0.86 & 0.452 & 5811 & 0.440 & 0.839 \\
\hline Site $(\mathrm{R} \times \mathrm{P})$ & 12 & 15.82 & 1.52 & 0.129 & 1.16 & 2.44 & 0.008 & 1452.7 & 1.58 & 0.001 \\
\hline Depth & 2 & 119.64 & 2.63 & 0.187 & 1.84 & 0.54 & 0.619 & 10658 & 1.90 & 0.127 \\
\hline $\mathrm{R} \times \mathrm{P}$ & 2 & 57.79 & 3.65 & 0.058 & 6.09 & 5.26 & 0.022 & 13216 & 9.10 & 0.001 \\
\hline $\mathrm{R} \times \mathrm{D}$ & 4 & 45.54 & 5.08 & 0.004 & 3.40 & 3.86 & 0.015 & 5605.7 & 4.41 & 0.001 \\
\hline $\mathrm{P} \times \mathrm{D}$ & 2 & 60.23 & 2.04 & 0.245 & 0.54 & 0.25 & 0.792 & 3796.3 & 1.52 & 0.243 \\
\hline $\mathrm{D} \times \mathrm{S}(\mathrm{R} \times \mathrm{P})$ & 24 & 8.96 & 0.86 & 0.655 & 0.88 & 1.85 & 0.018 & 1272 & 1.38 & 0.005 \\
\hline $\mathrm{R} \times \mathrm{P} \times \mathrm{D}$ & 4 & 29.55 & 3.30 & 0.027 & 2.20 & 2.5 & 0.069 & 2500.9 & 1.97 & 0.009 \\
\hline Residual & 108 & 10.43 & & & 0.476 & & & 920.37 & & \\
\hline
\end{tabular}

tion within each region and each level of depth revealed no consistent effects on herbivorous fish biomass. SNK tests of depth within each region and protection revealed that in 2 of the UAs (Catalunya and Menorca), herbivore biomass decreased with depth (SNK, p $<0.01$ for all comparions), whereas elsewhere depth had no consistent effect. Total biomass of predatory fish was greater inside the MPA than in the UA in only one of the regions (Catalunya; significant region $\times$ protection interaction term, $\mathrm{SNK}$, $\mathrm{p}<0.01$; Table 2, Fig. 3B). Total biomass of predatory fish was greater in shallow water $(5 \mathrm{~m})$ than at greater depths (15 or $30 \mathrm{~m})$, but again only in Catalunya (significant region $\times$ depth interaction term, SNK $\mathrm{p}<0.05$ for both comparisons; Table 2, Fig. 3B).

In our multivariate analysis of fish assemblages, the PERMDISP test indicated significant differences in the multivariate dispersion among groups $\left(F_{53,108}=\right.$
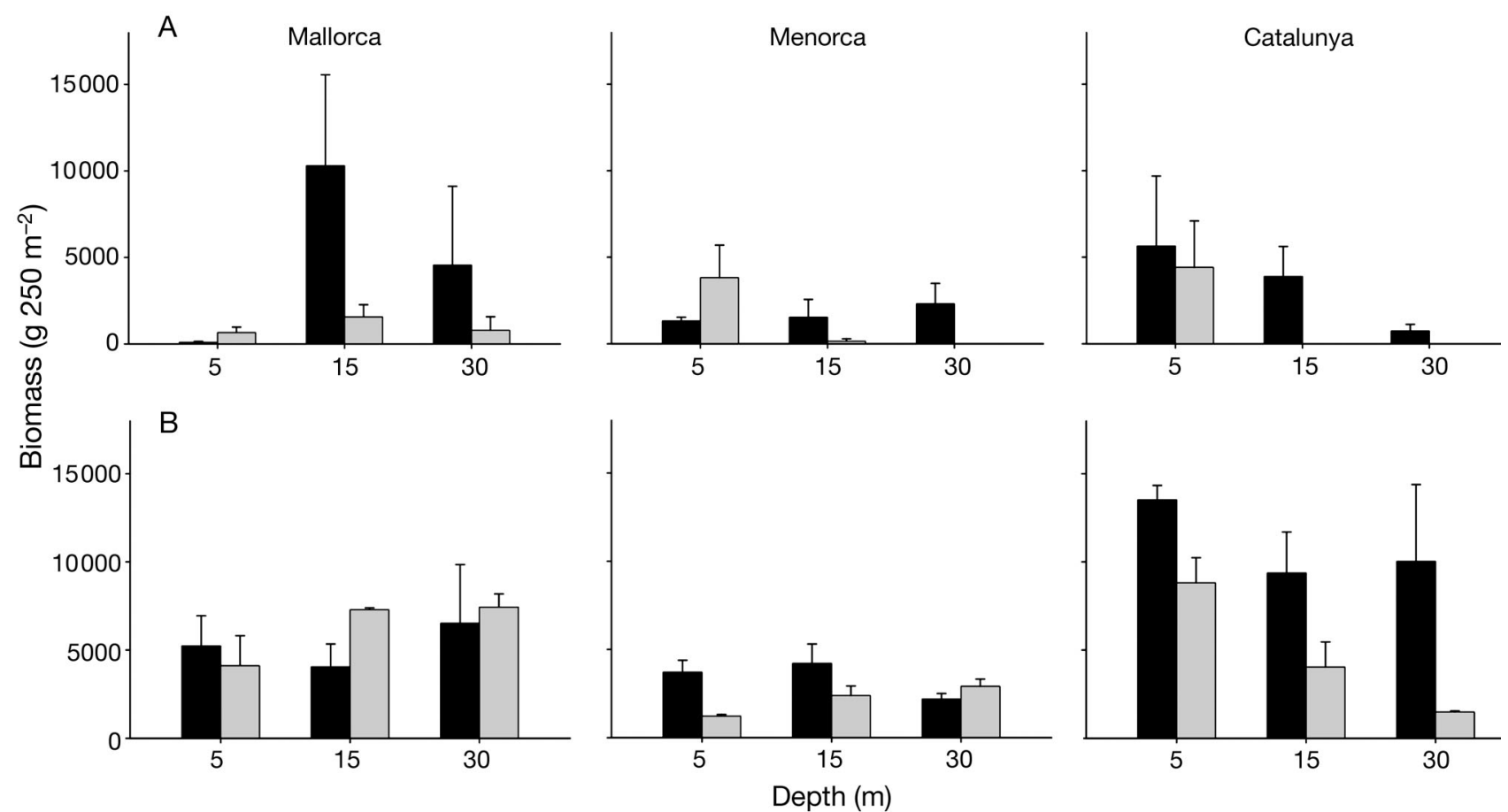

Fig. 3. Biomass (mean + SE) of (A) herbivorous fish and (B) urchin predatory fish at different depths $(5,15$ and 30 m) in marine protected areas (black bars) and unprotected areas (grey bars) in the 3 regions studied (ordered from south to north; Mallorca, Menorca and Catalunya) 
Table 3. Multivariate PERMANOVAs comparing the size-frequency distributions of the main sea urchin consumers Diplodus sargus, D. vulgaris and Coris julis among regions (R), depth (D), protection (P), site (S) and their interactions. Denominator terms for pseudo- $F$ tests in the analysis are given in Table 1. Bold text indicates a significant effect at $\mathrm{p}<0.05$

\begin{tabular}{|c|c|c|c|c|c|c|c|c|c|c|}
\hline \multirow{2}{*}{$\begin{array}{l}\text { Source of } \\
\text { variation }\end{array}$} & \multirow[t]{2}{*}{ df } & \multicolumn{3}{|c|}{ - Diplodus sargus } & \multicolumn{3}{|c|}{-Diplodus vulgaris } & \multicolumn{3}{|c|}{-Coris julis - } \\
\hline & & MS & Pseudo- $F$ & $\mathrm{p}$ & MS & Pseudo- $F$ & $\mathrm{p}$ & MS & Pseudo- $F$ & $\mathrm{p}$ \\
\hline Region & 2 & 1011.3 & 35.794 & 0.001 & 1172.9 & 5.033 & 0.001 & 2281.7 & 8.0895 & 0.002 \\
\hline Protection & 1 & 47.259 & 0.097 & 0.888 & 1209.1 & 1.079 & 0.413 & 1328.3 & 0.699 & 0.557 \\
\hline Site $(\mathrm{R} \times \mathrm{P})$ & 12 & 28.253 & 0.974 & 0.451 & 233.04 & 0.769 & 0.774 & 282.06 & 3.2795 & 0.001 \\
\hline Depth & 2 & 227.14 & 0.842 & 0.510 & 958.13 & 3.606 & 0.041 & 164.94 & 0.404 & 0.785 \\
\hline $\mathrm{R} \times \mathrm{P}$ & 2 & 485.24 & 17.175 & 0.001 & 1121 & 4.810 & 0.001 & 1901.4 & 6.7411 & 0.001 \\
\hline $\mathrm{R} \times \mathrm{D}$ & 4 & 269.76 & 6.516 & 0.002 & 265.7 & 0.719 & 0.667 & 408.14 & 3.3127 & 0.009 \\
\hline $\mathrm{P} \times \mathrm{D}$ & 2 & 42.722 & 0.811 & 0.535 & 499.91 & 0.695 & 0.586 & 524.68 & 0.115 & 0.077 \\
\hline $\mathrm{D} \times \mathrm{S}(\mathrm{R} \times \mathrm{P})$ & 24 & 41.401 & 1.427 & 0.060 & 369.59 & 1.220 & 0.142 & 123.2 & 1.4325 & 0.044 \\
\hline $\mathrm{R} \times \mathrm{P} \times \mathrm{D}$ & 4 & 52.676 & 1.272 & 0.304 & 719.57 & 1.947 & 0.078 & 167.05 & 1.3559 & 0.228 \\
\hline Residual & 108 & 29.012 & & & 302.91 & & & 86.006 & & \\
\hline
\end{tabular}

3.59, $\mathrm{p}=0.02)$. The PERMANOVA test also detected a significant interaction between region, protection and depth (Table 2). Together, the PERMDISP and PERMANOVA results indicate a clear 3way interaction that may be due to differences in location, differences in dispersion or a combination of the two (Anderson et al. 2008). PERMANOVA pair-wise tests were used to identify the effects of depth and protection within each region. Pair-wise tests showed that shallow $(5 \mathrm{~m})$ fish assemblages differed significantly from deep (30 m) assemblages in all regions irrespective of protection (PERMANOVA pair-wise tests, $\mathrm{p} \leq 0.05$ for all comparisons), except at the MPA in Catalunya, where fish assemblages were similar at all depths. Deep (30 m) fish assemblages differed between UAs and MPAs in all regions (PERMANOVA pair-wise tests, $\mathrm{p} \leq 0.02$ for all comparisons), whereas at shallower depths the effects of protection were not consistent across regions.

Analysis of the size-frequency distribution of each of the 3 main sea urchin consumers (Diplodus sargus, D. vulgaris and Coris julis) revealed a significant effect of protection in all species that varied with region (significant region $\times$ protection interaction term; Table 3, Fig. 4). D. vulgaris and C. julis generally showed higher abundances of small and/or medium size classes inside MPAs (PERMANOVA pairwise tests, $\mathrm{p}<0.05)$, with the exception of $C$. julis in Menorca and D. vulgaris in

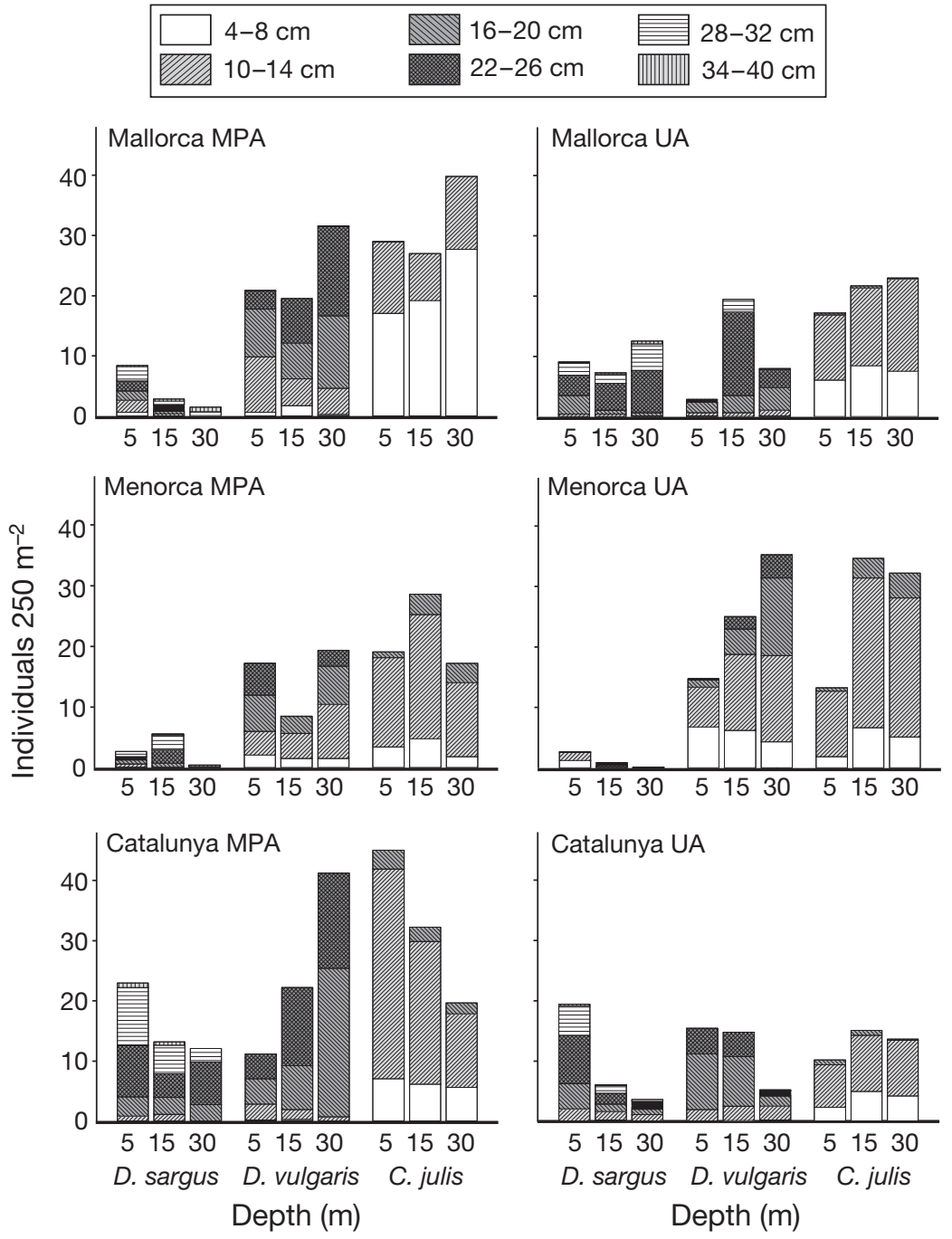

Fig. 4. Size-frequency distribution of the main urchin consumers (Diplodus sargus, D. vulgaris and Coris julis) at all depths $(5,15$ and $30 \mathrm{~m}$ ) in marine protected areas (MPAs) and unprotected areas (UAs) in the 3 regions studied (ordered from south to north; Mallorca, Menorca and Catalunya) 
Mallorca, where there were no differences in the size distribution of fishes between protected and unprotected sites (Fig. 4). D. sargus showed greater abundances of larger fish inside MPAs in Menorca and Catalunya, whereas the opposite was true in Mallorca (PERMANOVA pair-wise tests, $\mathrm{p}<0.05$ ). There was a significant effect of depth on the sizefrequency distribution of $D$. sargus that varied with region (significant depth $\times$ region interaction; Table 3 , Fig. 4). Large $D$. sargus individuals were more abundant in shallow water $(5 \mathrm{~m})$ than at greater depths in both Menorca and Catalunya, whereas this species had a similar size structure at all depths in Mallorca PERMANOVA pair-wise tests, $\mathrm{p}<0.05)$. We detected a significant but weak effect of depth on the size distribution of D. vulgaris (Table 3), with medium-sized individuals being more abundant in deep waters (30 m) than at intermediate depths (15 m; Fig. 4). Although we also detected a significant effect of depth in the size distribution of $C$. julis that varied with both region and level of protection (significant region $\times$ depth and protection $\times$ depth interaction; Table 3), no clear pattern could be discerned (Fig. 4).

\section{DISCUSSION}

Predation rates on juvenile urchins were influenced by protection from fishing in all regions, but only in shallow water; at greater depths, the effects of protection varied between regions. Rates of herbivory were not strongly affected by fishing activities, and generally decreased with depth in both protected and unprotected areas. We found no evidence of an increase in urchin predation by fishes with depth, or of an increase in the size of urchin predators with depth.

The significant effect of protection on urchin predation rates in shallow waters observed across all regions is consistent with the results of other studies that have directly measured predation rates on urchins inside and outside MPAs, all of which were performed at shallow depths (ca. 0.5 to $10 \mathrm{~m}$ ) and found a positive effect of protection (McClanahan et al. 1999, Shears \& Babcock 2002, Guidetti 2006). The greater effects of protection on urchin consumption rates detected in shallow waters in our study may be due to the fact that many of the key fish species involved in sea urchin predation are often targeted by extractive activities concentrated in these shallower waters, such as spearfishing and recreational angling from the shore or from small vessels (Morales-Nin et al. 2005, Lloret et al. 2008). Other studies have also found that shallow Mediterranean fish assemblages are the most sensitive to protection, as fishing efforts concentrate in these first meters of water (Claudet et al. 2011). Although the effects of protection on relative predation rates outside shallow water were not consistent, there was a general trend towards greater consumption of urchins inside MPAs across most depth and region combinations, suggesting that the pattern observed at $5 \mathrm{~m}$ may extend to all depths with time as fish populations continue to recover from fishing in protected areas. Indeed, in support of this conjecture, this trend was stronger in the 2 MPAs that have been established for the longest time, the Medes Islands in Catalunya (since 1983), and Cabrera in Mallorca (since 1991).

Although the effects of protection on predation rates in shallow water were consistent across all regions, we only detected a consistent positive effect of protection on the biomass of fishes that consume urchins in the Medes Islands MPA in Catalunya. Context-dependent differences in the response of predatory fishes to protection are quite common (e.g. Clemente et al. 2011). A number of managementrelated reasons may explain this in our study. Time since prohibition of fishing is an important determinant of the response of fish assemblages to protection (Micheli et al. 2004, Guidetti \& Sala 2007, Claudet et al. 2008), and the Catalunya MPA is the oldest one considered in this study by at least $8 \mathrm{yr}$. Moreover, the level of protection of the Catalunya MPA is greater than in the other 2 regions, because all extractive activities are prohibited in Catalunya, whereas some restricted commercial fishing is still permitted in the Mallorca and Menorca MPAs.

We did not detect any consistent depth-related patterns in predation at either MPAs or UAs. This contrasts with studies that have found predation rates to be 2 to 3 times higher in deeper waters (14 to $20 \mathrm{~m}$ ) than in shallower waters $(\leq 5 \mathrm{~m}$ ) (Linehan et al. 2001, Ryer et al. 2010). Differences in broad structural complexity may partly explain the disparity between these results and ours, as the availability of shelter is a key factor determining predation rates (Hixon \& Beets 1993), and both the study by Linehan et al. (2011) and Ryer et al. (2010) were performed in softsediment communities with relatively low structural complexity (from sand and mud to silt-covered occasional boulder outcrops). In contrast, our study was performed in structurally complex rocky reefs that generally provide refuges for both prey and predators at all depths (5 to $30 \mathrm{~m}$ ).

The size distribution structure of the 3 main urchin predators did not differ consistently across depths, 
indicating that the general pattern observed in other systems, where the mean size of individuals of fish species increases with depth (Macpherson \& Duarte 1991, Linehan et al. 2001), does not apply to these species. Although we did detect an effect of protection on the size distribution structure of the main urchin consumers, the lack of consistency across regions suggests that factors other than fishing are strongly influencing these patterns. Generally, the creation of MPAs tends to favour the larger size classes of target fish species (e.g. Garcia-Rubies \& Zabala 1990, Guidetti 2006), and this is what we found for Diplodus sargus in Menorca and Catalunya, whereas the opposite was true in Mallorca (larger D. sargus in UAs). The clearest effect of protection on the size structure of $D$. vulgaris and Coris julis was greater abundance of small and medium individuals within MPAs.

As expected, rates of herbivory and biomass of herbivorous fish were largely unaffected by protection - we only detected a near-significant trend towards greater herbivory in UAs. This is consistent with a meta-analysis by Micheli et al. (2004), which showed that herbivores commonly do not respond or respond negatively to fishing protection, particularly if they are not targeted by fisheries, and that top predators are often the most responsive trophic guild to protection. We found a general decrease in relative rates of fish herbivory with depth, confirming the results of a number of studies that show greater consumption of marine plants in relatively shallow waters around $5 \mathrm{~m}$ depth (Verlaque 1990, Tomas et al. 2005, Vergés et al. 2009). However, this bathymetric pattern was not consistent at all sites, indicating that factors other than depth are also influencing the feeding activity of herbivores. The grazing activity of herbivorous fish is known to vary greatly over naturally occurring temperature gradients at small scales (Smith 2008), and this may have also influenced feeding by Sarpa salpa in our study, as we observed important changes in the depth of the summer thermocline, which separates warm, shallow water and cooler, deeper water during the summer months, both among regions and sites.

In conclusion, our findings show that protection has pronounced effects on sea urchin predation rates by fishes in shallow waters. Because predator-urchin interactions can have important community-wide effects (e.g. Sala et al. 1998, Guidetti 2006), and herbivorous sea urchins are commonly most abundant in shallow habitats (Chelazzi et al. 1997, Tomas et al. 2004), an increase in sea urchin predation within shallow waters in MPAs can facilitate the mainte- nance of diverse and structurally complex algal communities. In contrast, the intensity of herbivory by fishes, which is increasingly being recognised as an important driver of algal community dynamics in temperate systems (Vergés et al. 2009, Taylor \& Schiel 2010), follows a general decrease with depth, and shows only weak negative effects with protection.

Acknowledgements. We thank J. Amengual (Parc Nacional de l'Arxipèlag de Cabrera), A. Grau (Conselleria d'Agricultura, Medi Ambient i Territori del Govern de les Illes Balears) and N. Buenaventura (Àrea Protegida de les Illes Medes) for giving us access and facilitating our work at the Cabrera, Nord de Menorca and Illes Medes MPAs. We are grateful to E. Cebrian for help with fieldwork and we thank 2 anonymous reviewers that improved the quality of the manuscript. This study was supported by Agència Catalana de l'Aigua (Departament de Medi Ambient i Habitatge, Generalitat de Catalunya) and GRACCIE project (CSD200700067). This is contribution No. 69 from the Sydney Institute of Marine Science.

\section{LITERATURE CITED}

Anderson M, Gorley R, Clarke K (2008) PERMANOVA+ for PRIMER. Primer-E, Plymouth

Aronson RB, Heck KL Jr (1995) Tethering experiments and hypothesis testing in ecology. Mar Ecol Prog Ser 121: 307-309

Babcock RC, Shears NT, Alcala AC, Barrett NS and others (2010) Decadal trends in marine reserves reveal differential rates of change in direct and indirect effects. Proc Natl Acad Sci USA 107:18256-18261

Baker R, Sheaves M (2007) Shallow-water refuge paradigm: conflicting evidence from tethering experiments in a tropical estuary. Mar Ecol Prog Ser 349:13-22

$>$ Bell JD (1983) Effects of depth and marine reserve fishing restrictions on the structure of a rocky reef fish assemblage in the Northwestern Mediterranean Sea. J Appl Ecol 20:357-369

Boudouresque C, Verlaque M (2001) Ecology of Paracentrotus lividus. In: Lawrence JM (ed) Edible sea urchins: biology and ecology. Elsevier Science, Amsterdam, p $177-$ 216

> Brokovich E, Ayalon I, Einbinder S, Segev N and others (2010) Grazing pressure on coral reefs decreases across a wide depth gradient in the Gulf of Aqaba, Red Sea. Mar Ecol Prog Ser 399:69-80

Cardona L, Lopez D, Sales M, De Caralt S, Diez I (2007) Effects of recreational fishing on three fish species from the Posidonia oceanica meadows off Minorca (Balearic archipelago, western Mediterranean). Sci Mar 71:811820

Chelazzi G, Serra G, Bucciarelli G (1997) Zonal recovery after experimental displacement in two sea urchins cooccurring in the Mediterranean. J Exp Mar Biol Ecol 212: $1-7$

Clarke K, Gorley R (2006) PRIMER v6. Plymouth Marine Laboratory, Plymouth

> Claudet J, Osenberg CW, Benedetti-Cecchi L, Domenici P and others (2008) Marine reserves: size and age do matter. Ecol Lett 11:481-489 
Claudet J, García-Charton JA, Lenfant P (2011) Combined effects of levels of protection and environmental variables at different spatial resolutions on fish assemblages in a marine protected area. Conserv Biol 25:105-114

> Clemente S, Hernández JC, Rodríguez A, Brito A (2010) Identifying keystone predators and the importance of preserving functional diversity in sublittoral rocky-bottom areas. Mar Ecol Prog Ser 413:55-67

Clemente S, Hernández JC, Brito A (2011) Context-dependent effects of marine protected areas on predatory interactions. Mar Ecol Prog Ser 437:119-133

Connell JH (1975) Some mechanisms producing structure in natural communities: a model and evidence from field experiments. In: Cody ML, Diamond J (eds) Ecology and evolution of communities. Harvard University Press, Cambridge, MA, p 406-490

Edgar GJ, Barrett NS (1997) Short term monitoring of biotic change in Tasmanian marine reserves. J Exp Mar Biol Ecol 213:261-279

Farina S, Tomas F, Prado P, Romero J, Alcoverro T (2009) Seagrass meadow structure alters interactions between the sea urchin Paracentrotus lividus and its predators. Mar Ecol Prog Ser 377:131-137

Francour P (1994) Pluriannual analysis of the reserve effect on ichthyofauna in the Scandola Natural Reserve (Corsica, Northwestern Mediterranean). Oceanol Acta 17: 309-317

Froese R, Pauly D (2005) Fishbase. Available at www.fishbase.org

García-Charton JA, Pérez-Ruzafa A (2001) Spatial pattern and the habitat structure of a Mediterranean rocky reef fish local assemblage. Mar Biol 138:917-934

- García-Charton JA, Pérez-Ruzafa A, Sánchez-Jerez P, Bayle-Sempere JT, Reñones O, Moreno D (2004) Multiscale spatial heterogeneity, habitat structure, and the effect of marine reserves on Western Mediterranean rocky reef fish assemblages. Mar Biol 144:161-182

Garcia-Rubies A, Zabala M (1990) Effects of total fishing prohibition on the rocky fish assemblages of Medes Islands marine reserve (NW Mediterranean). Sci Mar 54: 317-328

> Guidetti P (2006) Marine reserves reestablish lost predatory interactions and cause community changes in rocky reefs. Ecol Appl 16:963-976

Guidetti P, Sala E (2007) Community-wide effects of marine reserves in the Mediterranean Sea. Mar Ecol Prog Ser 335:43-56

> Harmelin JG, Bachet F, Garcia F (1995) Mediterranean marine reserves: fish indices as tests of protection efficiency. PSZNI: Mar Ecol 16:233-250

Harmelin-Vivien M, Harmelin JG, Chauvet C, Duval C and others (1985) Visual evaluation of fish communities and populations. Methods and problems. Rev Ecol Terre Vie 40:467-539

> Hay ME, Colburn T, Downing D (1983) Spatial and temporal patterns in herbivory on a Caribbean fringing reef - the effects on plant distribution. Oecologia 58:299-308

> Hereu B, Zabala M, Linares C, Sala E (2004) Temporal and spatial variability in settlement of the sea urchin Paracentrotus lividus in the NW Mediterranean. Mar Biol 144:1011-1018

Hixon MA, Beets JP (1993) Predation, prey refuges, and the structure of coral reef fish assemblages. Ecol Monogr 63: $77-101$

Linehan JE, Gregory RS, Schneider DC (2001) Predation risk of age-0 cod (Gadus) relative to depth and substrate in coastal waters. J Exp Mar Biol Ecol 263:25-44

Lloret J, Zaragoza N, Caballero D, Font T, Casadevall M, Riera V (2008) Spearfishing pressure on fish communities in rocky coastal habitats in a Mediterranean marine protected area. Fish Res 94:84-91

> Macpherson E, Duarte CM (1991) Bathymetric trends in demersal fish size: is there a general relationship? Mar Ecol Prog Ser 71:103-112

> McClanahan TR, Muthiga NA, Kamukuru AT, Machano H, Kiambo RW (1999) The effects of marine parks and fishing on coral reefs of northern Tanzania. Biol Conserv 89: 161-182

McIvor CC, Odum WE (1988) Food, predation risk, and microhabitat selection in a marsh fish assemblage. Ecology 69:1341-1351

> Menge BA, Farrell TM (1989) Community structure and interaction webs in shallow marine hard-bottom communities - tests of an environmental stress model. Adv Ecol Res 19:189-262

Menge BA, Olson AM (1990) Role of scale and environmental factors in regulation of community structure. Trends Ecol Evol 5:52-57

Menge BA, Sutherland JP (1987) Community regulation: variation in disturbance, competition, and predation in relation to environmental stress and recruitment. Am Nat 130:730-757

Micheli F, Amarasekare P, Bascompte J, Gerber LR (2004) Including species interactions in the design and evaluation of marine reserves: some insights from a predatorprey model. Bull Mar Sci 74:653-669

> Morales-Nin B, Moranta J, Garcia C, Tugores MP, Grau AM, Riera F, Cerda M (2005) The recreational fishery off Majorca Island (Western Mediterranean): some implications for coastal resource management. ICES J Mar Sci 62:727-739

> Morato T, Afonso P, Lourinho P, Barreiros JP, Santos RS, Nash RDM (2001) Length-weight relationships for 21 coastal fish species of the Azores, north-eastern Atlantic. Fish Res 50:297-302

> Pinnegar JK, Polunin NVC (2000) Contributions of stableisotope data to elucidating food webs of Mediterranean rocky littoral fishes. Oecologia 122:399-409

Pinnegar JK, Polunin NVC, Francour P, Badalamenti F and others (2000) Trophic cascades in benthic marine ecosystems: lessons for fisheries and protected-area management. Environ Conserv 27:179-200

Prado P, Tomas F, Alcoverro T, Romero J (2007) Extensive direct measurements of Posidonia oceanica defoliation confirm the importance of herbivory in temperate seagrass meadows. Mar Ecol Prog Ser 340:63-71

Ruitton S, Francour P, Boudouresque C (2000) Relationships between algae, benthic herbivorous invertebrates and fishes in rocky sublittoral communities of a temperate sea (Mediterranean). Estuar Coast Shelf Sci 50:217-230

> Ruiz GM, Hines AH, Posey MH (1993) Shallow water as a refuge habitat for fish and crustaceans in nonvegetated estuaries: an example from Chesapeake Bay. Mar Ecol Prog Ser 99:1-16

> Ryer CH, Laurel BJ, Stoner AW (2010) Testing the shallow water refuge hypothesis in flatfish nurseries. Mar Ecol Prog Ser 415:275-282

Sala E (1997) Fish predators and scavengers of the sea urchin Paracentrotus lividus in protected areas of the north-west Mediterranean Sea. Mar Biol 129:531-539 
Sala E, Boudouresque C (1997) The role of fishes in the organization of a Mediterranean sublittoral community. I. Algal communities. J Exp Mar Biol Ecol 212:25-44

Sala E, Zabala M (1996) Fish predation and the structure of the sea urchin Paracentrotus lividus populations in the NW Mediterranean. Mar Ecol Prog Ser 140:71-81

Sala E, Boudouresque CF, Harmelin-Vivien M (1998) Fishing, trophic cascades, and the structure of algal assemblages: evaluation of an old but untested paradigm. Oikos 82:425-439

Shears NT, Babcock RC (2002) Marine reserves demonstrate top-down control of community structure on temperate reefs. Oecologia 132:131-142

Shears NT, Babcock RC (2003) Continuing trophic cascade effects after 25 years of no-take marine reserve protection. Mar Ecol Prog Ser 246:1-16

Sloan NA, Aldridge TH (1981) Observations on an aggregation of the starfish Asterias rubens L in Morecambe Bay, Lancashire, England. J Nat Hist 15:407-417

Smith TB (2008) Temperature effects on herbivory for an Indo-Pacific parrotfish in Panama: implications for coral-algal competition. Coral Reefs 27:397-405

Stelzenmuller V, Maynou F, Martin P (2007) Spatial assessment of benefits of a coastal Mediterranean Marine Protected Area. Biol Conserv 136:571-583

Taylor DI, Schiel DR (2010) Algal populations controlled by fish herbivory across a wave exposure gradient on southern temperate shores. Ecology 91:201-211

Tomas F, Romero J, Turon X (2004) Settlement and recruitment of the sea urchin Paracentrotus lividus in two con-

Editorial responsibility: Lisandro Benedetti-Cecchi, Pisa, Italy trasting habitats in the Mediterranean. Mar Ecol Prog Ser 282:173-184

- Tomas F, Turon X, Romero J (2005) Seasonal and small-scale spatial variability of herbivory pressure on the temperate seagrass Posidonia oceanica. Mar Ecol Prog Ser 301: 95-107

Tomas F, Cebrian E, Ballesteros E (2011) Differential herbivory of invasive algae by native fish in the Mediterranean Sea. Estuar Coast Shelf Sci 92:27-34

> Vergés A, Alcoverro T, Ballesteros E (2009) Role of fish herbivory in structuring the vertical distribution of canopy algae Cystoseira spp. in the Mediterranean Sea. Mar Ecol Prog Ser 375:1-11

Verlaque M (1990) Relations entre Sarpa salpa (Linnaeus, 1758) (Téléostéen, Sparidae), les autres poissons broteurs et le phytobenthos algal Méditerranéen. Oceanol Acta 13:373-388

- Willis TJ, Millar RB, Babcock RC (2003) Protection of exploited fish in temperate regions: high density and biomass of snapper Pagrus auratus (Sparidae) in northern New Zealand marine reserves. J Appl Ecol 40:214-227

> Witman JD (1987) Subtidal coexistence - storms, grazing, mutualism, and the zonation of kelps and mussels. Ecol Monogr 57:167-187

Witman JD, Dayton PK (2001) Rocky subtidal communities. In: Bertness M, Gaines SD, Hay M (eds) Marine community ecology. Sinauer, Sunderland, MA, p 339-366

> Witman JD, Grange KR (1998) Links between rain, salinity, and predation in a rocky subtidal community. Ecology 79:2429-2447

Submitted: June 6, 2011; Accepted: January 13, 2012 Proofs received from author(s): March 20, 2012 